\title{
Marital Name Changing: Delving Deeper into Women’s Reasons
}

\author{
Megan M. Keels, Rebecca S. Powers* \\ Department of Sociology, East Carolina University, Greenville, USA \\ Email: megankeels@alumni.ecu.edu, "powersr@ecu.edu
}

Received September 24 $4^{\text {th }}$, 2013; revised October 24 ${ }^{\text {th }}$, 2013; accepted November $1^{\text {st }}, 2013$

\begin{abstract}
Copyright (C) 2013 Megan M. Keels, Rebecca S. Powers. This is an open access article distributed under the Creative Commons Attribution License, which permits unrestricted use, distribution, and reproduction in any medium, provided the original work is properly cited.
\end{abstract}

\begin{abstract}
Using a mixed method approach, this study examines women's reasons for the traditional practice of marital name changing. We utilize data collected via a questionnaire administered to first-year college students at a southeastern US public university and data gathered from in-depth interviews with recent college graduates. The quantitative results show that the reasons given for marital name changing are closely tied to social norms. The results from the qualitative analyses reveal more specifically how social norms direct the practice of marital name changing. Together the findings show that women's perceptions of their family's expectations are a key reason motivating them to practice marital name changing. However, in both samples, respondents express mixed and sometimes inconsistent reasons regarding marital name changing. Respondents emphasize the importance of adhering to the tradition while also reporting that they did not consider marital name changing as an important issue. These findings indicate the multifaceted quality of the issue. Together, the results illustrate how social norms shape people's personal decision about marital name changing while also showing how the decision made by people shapes society.
\end{abstract}

Keywords: Marital Name Changing; Social Norms; Name Change; Tradition

\section{Introduction}

Names are important to people, and yet adults in the US can legally change a name with relatively little complication. There are various reasons why someone might want to legally change names and the majority of women do so at marriage by dropping their maiden name and taking their husband's surname (Emens, 2007; Gooding \& Kreider, 2010; Scheuble, Johnson, \& Johnson, 2012). Like other cultural traditions, marital name changing is a multifaceted issue. On the one hand, the emphasis on individualism in US culture implies the appropriateness of keeping one's birth name as a means of maintaining personal identity and family ties. On the other hand, social norms about marriage are unambiguous in the expectation that women should unite themselves by name with their husband and children.

Confirmation of the issue's cultural salience is everywhere in popular media outlets. For example, endorsement of traditional marital name changing is easily found on the Internet social media site Facebook with postings by engaged women expressing excitement at becoming a Mrs. His-Last-Name, on Internet websites such as MissNowMrs.com that sells a namechanging service to newly married women and on various Internet blogs (see e.g., postings on huffingtonpost.com). At the same time, we see high profile women in a variety of occupations shun the tradition. A preference for married women retaining their maiden name is publicly displayed by politicians (e.g., Sonia Sotomayor, Deborah Wasserman Schultz), hosts of television news shows (e.g., Melissa Harris-Perry, Barbara Walters), actresses (e.g., Nicole Kidman, Meryl Streep) and professional athletes (e.g., Kerri Walsh Jennings, Misty

${ }^{*}$ Corresponding author.
May-Treanor). Thus, while the practice of marital name changing continues to be a common practice-a social norm-it is also openly resisted and this fact emphasizes the importance of names to people.

An effective illustration of the importance of names was shown in the magazine National Geographic where the most common US surnames were presented in the form of a map that displayed the distribution of people's surnames by state. The map was part of a research study that collected data on surnames to track immigration patterns and for genealogical purposes (Cheshire, Longley, \& Mateos, 2011). The researchers created a website for people to find "hot spots for surnames around the globe” (p. 21), which further emphasizes the level of interest that names hold. While a patriarchal social system has daughters carrying their father's last name (until marriage) it is obvious that the commonness of surnames in the US is intricately linked to the tradition of marital name changing.

Cultural traditions exist in a social context that experiences social change. For example, new state laws legalizing same-sex marriage require marriage license forms to be redone so they are sex neutral (Emens, 2011). This paperwork update provides an opportunity to include information on the form about legal options for marital name changing that would potentially raise awareness about choices that are available for all couples. Nevertheless, sometimes cultural traditions persist regardless of social and legal changes. In the present study, we draw on a framework of symbolic interactionism, social constructionism and Feminist theory to explore the reasons for marital name changing with the intention of gaining insight into the structure of social norms and cultural traditions. We utilize a mixed method approach and draw on both qualitative and quantitative data to delve deeper into the reasons women give for marital name 
changing.

\section{Framework and Prior Research}

Sociologists emphasize the importance of the socialization process and language in constructing social reality. People learn the meanings of symbols in social interactions and these social objects are used to represent whatever people agree that they should represent. From the perspective of symbolic interactionism, language allows people to actively create society (Berger \& Luckman, 1966; Blumer, 1969; Garfinkel, 1967, 1984; Goffman, 1959; Schutz, 1932, 1967) and this includes constructing social norms that reflect and shape the social context. The social norm of marital name changing is linked to a patriarchal social structure that includes gendered societal expectations (Kimmel, 2011). It is a socially constructed expectation that women will prioritize marriage over their personal identities, as displayed in their last name, and practice the tradition of marital name changing (Smith, 1987).

From a feminist perspective, participating in marital name changing reinforces gender inequality because a woman's previously established single person identity is considered subordinate to the new married status (Emens, 2007; Smith, 1987). Historically, the legal doctrine of coverture enforced women's subordinate status by restricting the rights of married women (Hoff, 1991; Kerr, 1992; Million, 2003). In the mid ninetieth century, the well-known abolitionist, lecturer and suffragistLucy Stone challenged the status quo by keeping her surname after marriage (Hoff, 1991; Kerr, 1992; Million, 2003). Over one hundred years later, in 1975 it became legal for a married woman to keep her birth name, however; current public records show that the majority of women take their husband's surname at marriage (Gooding \& Kreider, 2010; Kopelman, Shea-Van Fossen, Paraskevas, Lawter, \& Prottas, 2009). The fact that most women follow the tradition of marital name changing provides evidence of the power and pervasiveness of the gender socialization process.

A recent study collected data from college students in two regions of the US to examine both attitudes and plans toward marital name changing across place and time (Scheuble et al., 2012). The results revealed that Midwest respondents in 2006 held more traditional attitudes compared to Midwest respondents in 1990, and were more likely to agree that marital name changing indicated a greater commitment to marriage. The analysis across regions showed that women respondents who lived in the eastern US were more likely to report plans to keep their name at marriage compared to those living in the Midwest. Research by Gooding and Kreider (2010) found that women living in the Northeast or Western part of the country were more likely to keep their own surname or combine surnames compared to women living in the South. A content analysis using wedding announcements published in The New York Times in the 1980's and 1990's, and in the years 2001-2005 found a nonlinear pattern (i.e., not systematic across time) for the percent of brides choosing to keep their birth name rather than participate in marital name changing (Kopelman et al., 2009). Together these findings suggest that the extent of adherence to a cultural tradition like marital name changing is affected by the place of residence and by social change across time.

A research study by Scheuble and Johnson (1993) conducted personal interviews with college students at a small US Midwest college. The majority (81.6\%) of women respondents planned to change their name upon marriage (p. 751). However, the results showed that women respondents who expected to marry later, planned on liberal work roles after childbirth, were from larger communities, had mothers with higher education levels, and held non-traditional gender role attitudes were more likely to be accepting of various name changing practices. Also, women respondents were significantly more likely than were men respondents to believe it is acceptable for a woman to keep her maiden name at marriage. According to all respondents, it would be acceptable for the bride to keep her name at marriage if she likes her maiden name, if she does not like her husband's name, if she is older when she marries, and/or if she wants to keep her own family name going. These findings reveal a variety of reasons considered acceptable for deviating from the social norm of name changing.

Prior research shows that women participate in marital name changing because of tradition, family values and pressure from society (Blakemore, Lawton \& Vartanian, 2005; Scheuble \& Johnson, 1993). Several studies have reported that marital name changing is more likely for women with lower levels of education (Gooding \& Kreider, 2010; Hoffnung, 2006; Scheuble \& Johnson, 1993), and report a strong positive correlation with women's educational attainment and rejecting the practice of marital name changing (Gooding \& Kreider, 2010). Scheuble and Johnson's (1993) study found that the practice of marital name changing was more likely for women who marry at a young age and for women who were not familiar with egalitarian lifestyles. Research by Blakemore et al., (2005) showed that women who expressed a strong drive to marry, who valued the role of being a parent over a career and who held traditional values were more likely to expect to change their name. Hoffnung's (2006) study found that marital name changing was likely for women who were Catholic, had mothers with only a high school education, and who stated they wanted to have children early in their marriage. This study reported that respondents did not consider their personal identity tied to their birth name nor did they think that marital name changing hindered progress toward gender equality in society.

Taken together, this review of the literature shows mixed findings suggesting that marital name changing is a multifaceted issue. Disentangling the ideas about this social norm is important for understanding its creation and perpetuation. The intention of the present study is to contribute to the literature with a mixed methods analysis that allows us to delve deeper into the reasons women give for participating in the traditional practice of marital name changing.

\section{Methodology}

For this study, two types of data are employed to investigate reasons for marital name changing: a quantitative secondary data set and a qualitative data set collected via in-depth interviews. A mixed method approach allows for comparison of results across two separate sets of data for purposes of strengthening and complementing the findings (Johnson \& Onwuegbuzie, 2004; Plano Clark, Garrett, \& Leslie-Pelecky, 2010). First, we carried out a pilot study using open-ended questions about reasons for marital name changing administered to students enrolled in Sociology classes at a medium-sized southeastern US public university. From these responses, a content analysis was conducted to ascertain patterns. Secondly, we compiled a list of reasons documented in prior literature on name changing. By 
comparing the pilot study results to those found in previous studies, twelve different reasons for marital name changing were determined and these reasons were used for developing the quantitative questionnaire and the qualitative interview script.

\section{Quantitative Sample}

During the fall semester of 2007, questionnaires were administered to first year and sophomore year college students enrolled in fifteen sections of lower division Sociology classes at a medium-sized southeastern US public university. Almost all of the 673 students participated (response rate of 98.5\%). For this study, only questionnaires with complete data were included and this produced a sample of 355 women and 168 men. Given that our focus is on women's reasons for changing their name upon marriage the sample was restricted to women respondents. Information about the respondent's race/ethnicity, high school graduation year, type of high school attended, and the city/state of their high school were collected as a means of determining demographic characteristics. Due to the limitations of the data, we had to restrict our sample. Thus, the final quantitative sample includes 129 white women, ages 18 - 19 years old, who graduated from public high schools and were first year college students.

\section{Qualitative Sample}

We employed a qualitative method approach and conducted in-depth interviews in 2011 with a sample of women who were engaged to be married or recently married. Using a snowball sampling technique, twenty-one individuals were contacted, five did not respond, and the others agreed to participate in the study. This effort resulted in a sample of sixteen women who had on average lived in the southeastern part of the US for ten years and were ages 22 - 31 years old. Over half (56\%) of the women were married and the rest (44\%) were engaged to be married. All of the respondents had attended college with most (75\%) completing a Bachelor's degree and three (19\%) had earned a Master's degree.

\section{Measurement}

Naming expectations are measured by asking questionnaire respondents the question, "If you get married, how likely are you to keep your name, drop your name or hyphenate your names?" To measure reasons for marital name changing, respondents were asked "When a woman gets married, do you think that dropping her maiden name and taking her husband's last name is..." with "yes/no" choices to a list of twelve statements that were possible reasons. Each of the reasons were dichotomized for the analyses as $1=$ yes and $0=$ no variables. Open-ended questions were asked in the face-to-face interviews to measure respondents' perceptions of and compliance with 1) social norms, 2) gender norms, 3) marriage traditions, and 4) socialization practices.

\section{Results}

\section{Quantitative Questionnaire}

Results from the questionnaire revealed that the majority (90\%) of women respondents stated that they are likely to drop their birth name upon marriage. However, the options about name changing were not mutually exclusive, and we found some ambiguity regarding women's expectations about whether they will drop, hyphenate, or keep their own last name at marriage. Results show that fifteen percent of respondents state they are likely to hyphenate their last names and thirteen percent are likely to keep their maiden name. This indicates that some respondents selected multiple contrasting options and this could be due to respondent error or indecisiveness.

Table 1 shows the frequency distributions for the twelve reasons for marital name changing, the extent of consensus, and the significant differences. The results are presented in rank order from the highest percent of respondents agreeing to a reason to the lowest percent agreeing. The most agreed upon statement about marital name changing is that it is a marriage practice that families expect (91\%). The lowest percentage (3\%) of respondents expressed agreement for the following two reasons: giving up the woman's identity and giving the husband power over the wife. The results in the shaded rows show high levels of consensus (i.e., at least 80\%) for the following reasons for marital name changing: giving the husband power over the wife (no =97\%), giving up the woman's identity (no =97\%), $a$ marriage practice that families expect (yes $=91 \%$ ), a traditional act that should be honored (yes = 83\%), a good way to build family unity (yes $=82 \%$ ), and easier than having two names (yes $=81 \%$ ).

For the reasons that lacked consensus we carried out a paired comparison analysis of percent differences and the estimated T-score showed significant differences for two reasons. Significantly more respondents agreed than disagreed that marital name changing is important if the couple is going to have children (yes $=67 \%$ ) and significantly fewer agreed than disagreed that name changing is a disadvantage if she has already built a career (yes $=33 \%$ ). Mixed results were found for the following

\section{Table 1.}

Percent of respondents agreeing with reason for marital name changing $(\mathrm{N}=129)$.

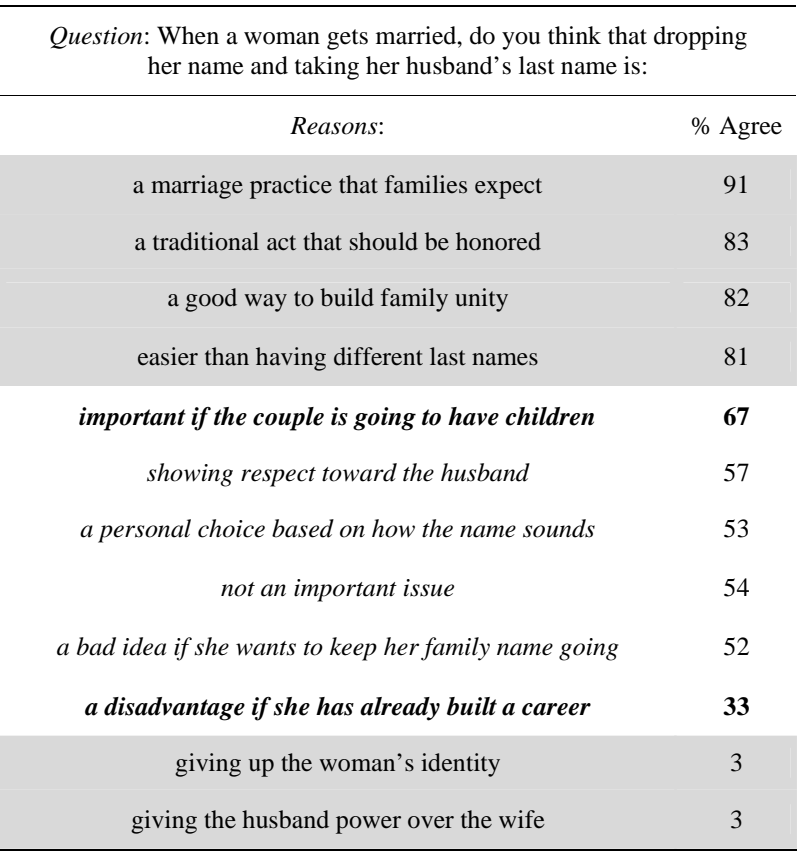

Notes: Gray shading indicates consensus of responses at $>80 \%$ and italicized responses indicate lack of consensus; bolded italicized indicates significant T-score percent difference (99\% confidence level). 
four reasons for marital name changing: showing respect toward the husband, a personal choice based on how the name sounds, not an important issue, and a bad idea if she wants to keep her family name going.

The analyses of the quantitative data show that respondents have various reasons for why they would change their name at marriage. Some of the reasons thematically support one another and some are inconsistent with each other. This suggests that allowing women to respond in their own words may enhance our understanding of the reasons for marital name changing and the results of the qualitative analysis are presented next.

\section{Qualitative Data Themes}

Analyses of the qualitative data included open coding and thematic development (Plano Clark et al., 2010). The results revealed two main themes of Social Expectations and Identity. The first main theme, Social Expectation is comprised of the subthemes: family expectations, family unity, tradition, compliance, and heteronormativity. The second main theme, identity has the subthemes: personal identity, family heritage, career and religion. In the following presentation of results all of the respondents are given pseudonyms to ensure anonymity.

Within the first main theme Social Expectations, the importance of family members in the socialization process was evident. The women interviewed frequently mentioned family expectations as a reason for their marital naming decision. This idea is illustrated by Parker, a 22-year-old engaged woman who stated:

"I guess both of us come from families that have done that, and I guess in our... you know families, no one has ever not taken the last name so it not something that was ever thought about. I guess we would have to have good reasoning behind [keeping the name] and we wouldn't so therefore they might be a little bit hesitant about it so..."

Respondents expressed the idea that they were supposed to take their spouse's name to please their families and maintain family harmony. This is demonstrated with the following statement by Cameron, a 24-year-old engaged woman:

"My family is very conservative, so I think that they would expect it... The first time that they introduced us to their friends after we got engaged was this is the future Mr. and Mrs. His Name and went way traditional with it and completely dropped my first name too which was weird. [Laughs] So they wouldn't have expected anything different so we never even had the conversation. So I think that it would be a huge discussion if I were to try and not change my name with my family".

These results show how family members influence and socialize each other. Respondents expressed that parents clearly endorsed the traditional practice of marital name changing and assumed there would be negative consequences for not adhering to expectations.

The subtheme of family unity emerged as a reason for marital name changing. The following excerpts illustrate the finding that respondents' thought that sharing a name is an important component for the formation of a family and for enhancing $\mathrm{fa}$ mily unity. For example, Jayden, a 24-year-old engaged woman stated:

"I'm more so just doing it because I think that when you start a new family the name is an important symbol of your unity as a family... I want to have the feeling of family unity of being the Ballards'... so I think that it is more... I want to be a cohesive family unit. I guess it's that feeling or belief that is the real reason or main reason why I want to change my name".

Another example of family unity is shown in the response from Hayden, a 24-year-old married woman who is still contemplating name changing who stated:

"I can see now how it can affect [family unity] for little things, like Charles likes to call us the Wilsons' but we're not the Wilsons' so that bothers him a lot. So it does affect family harmony because it's a rip and when we have kids it will be important because I want them to have our name, not just his name or not just my name. So I suppose that's important”.

It is notable that even the respondents that considered themselves non-traditional (i.e., they were career oriented, welleducated and/or self-identified as feminists), wanted to have the same name as their husband because they thought it was important for family unity.

The subtheme of tradition demonstrates how respondents perceived the social norm of marital name changing and how socialization perpetuates the practice. For example, Emerson, a 32-year-old married woman stated:

"I think just having seen other family members; cousins and so on get married prior to me and just having known the background of my parents and their siblings and so on and so forth. I guess yeah, in a way I guess you could look at that as tradition because it was something that always happened and always occurred".

The emotional component underlying adherence to tradition was also demonstrated by the enthusiasm expressed by respondents. For example, Jordan showed heightened emotion when referring to tradition by the way she stressed words and used non-verbal communication. She stated: "Ultimately I like the tradition, I like the idea of it, I like the whole idea of I'm going to be a part of you... I never struggled with it at all. It was never like do I do it, do I not?" Here, the respondent gets excited, her voice increases, her eyes widen, and she smiles when talking about liking the tradition of marital name changing, its importance as a part of marriage and being a part of her husband. Most of the interviewees responded in a similar way when they spoke about following the tradition of name changing. These findings provide insight into the social construction of reality and illustrate the emotional part of the tradition of marital name changing that is captured in names.

Compliance was a prominent subtheme that emerged in the analysis. To illustrate, Emerson, a 32-year-old married woman stated: "And changing my name was not something that I ever questioned, I know other people choose to keep their last name or choose to hyphenate, but that was just never something that I guess was questioned or that I was concerned with.” This type of statement was typically accompanied by the respondent's nonchalant body gestures (i.e., shrugged shoulders, lifted eyebrows, flipped up hands) and apathetic tone of voice. Respondents expressed that they did not give the topic of name changing much thought and it was not something that concerned them. To support this position, the women alluded to the fact that they have assumed they would change their name as a matter of practicing tradition in our society. For example, Dakota, a 23year-old engaged woman stated, "I think it is almost instinctual, it is something that I feel I am supposed to do." These types of statements indicate a level of compliance to a social norm that surpasses the intentional thought respondents gave to the ideas of family unity and personal identity.

The last subtheme of Social Expectations is heteronormativ- 
ity - the desire for an outward display of marriage. Respondents wanted other people to know and recognize that they are married and seriously committed to their husbands. These types of statements were ones in which the women showed the most enthusiasm when speaking about name changing. For example, Logan, a 25-year-old married woman stated, "I want people to know that I am married, that my name has changed, and that I am married to my husband." The respondent's excitement was shown with her voice changing to a higher pitch, her hand tapping the table with each phrase and smiling as she spoke. Another example of heteronormativity is shown in the response from Cameron, a 24-year-old engaged woman who stated:

'I want people to know that we're together and that I' $m$ his wife. I think I want that title and I want to be Mrs. Bob Smith if that's what you want to call it. And I am fine taking on his name to be able to have that identity with us being together".

The respondents perceived societal level benefits from being a married person and changing their name contributes to being socially acknowledged as married. For example, Emerson, a 32-year-old married woman stated, "And that [marital name changing] was kind of like one of those goal achievement types of things and that was just kind of how I viewed it."

The second main theme Identity is comprised of the subthemes personal identity, family heritage, career and religion. The respondents emphasized their personal identity by stating that their birth name was important to them and it shaped how they felt perceived by society. An example of this is shown by Avery, a 28-year-old married woman who stated,

"It is a little emotional like I said, it is sad because you are completely changing the surface of how people know you. When I call people they don't always recognize who you are and that's hard and learning your new name and changing everything about you was not fun and not easy. So it's the frustration, the loss of your sense of identity for the short amount of time that I think it takes for you to overcome that."

In describing personal identity, Hayden, a 24-year-old married woman stated, "I've been me my whole life and it was a little bit hard for me to give up my name and change to a new name. Which for what I see, is not a very big reason." These types of statements demonstrated the regret some respondents expressed in losing the personal identity that is linked to their birth name.

Respondents stated that their birth name was important to them in terms of their family heritage. For example, Ryan, a 24year-old engaged woman stated, "And I am very Italian and I am very proud of that and I love my heritage, and I don't really want to lose that, I just don't want to go from being an Italian to all white.” Likewise, Peyton, a 24-year-old engaged woman stated:

"Sure, I'm really proud of my family and heritage and everyone knows me as Peyton Jazzy and it is such a different name, but I've never disliked it so thinking about how I would feel being called something else, I took that into consideration."

These respondents' considered how changing their name would affect the tie to their family heritage indicating that names carry meaning for people across time and that some people feel strongly about the link.

The respondents stated that their careers were connected to their identity and they had considered their professional lives in light of marital name changing. This is best illustrated with the statement by Jayden, a 24-year-old engaged woman:

"I thought about, I will have a couple publications under my maiden name by the time we get married, just two I think, and it kind of stings to 'lose' those publications so I am toying with idea of keeping it hyphenated Smith-Jones for publications only like nowhere else, but then that gets confusing too, and it is only two publications so I might just make the switch and say screw it".

Although Jayden will be a professional after graduation, she has decided to take her husband's name upon marriage. Her statement about weighing the career-related consequences of name changing illustrates the type of personal debate undertaken by many of the women interviewed.

The subtheme of religion was another reason influencing the decision about marital name changing. For example, Casey, a 24-year-old engaged woman stated, "I think that if I didn't believe what I believe that I may not change my name... there is a meaning and a motive for it." This illustrates that marital name changing serves as a symbol of following a belief system. As Cameron, a 24-year-old engaged woman stated, "But as far as the tradition of the name change and us being one household and the way marriage was said to be, it's the religious aspect of me taking his name that has played a big part of it." This finding illustrates the importance of religion for the interviewees' decision to change names. Taken together, these findings show that there are various reasons for supporting the practice of marital name changing. The lack of a single theme emerging indicates the multifaceted quality of this social norm.

\section{Discussion}

The present study sought a deeper understanding of the reasons for the traditional practice of marital name changing. The results contribute to the literature by utilizing a mixed methods approach that reveals the multifaceted quality of marital name changing. The responses from women in the interview data show that the reasons given for name changing are not reasons that are easily captured by categories included in a questionnaire. Using the qualitative data delivers depth to the study while the quantitative data gives the study breadth.

Overall, there is agreement in the two samples of data with the majority of respondents expecting to follow (or have already followed) the tradition of marital name changing. This is consistent with previous research findings. Family expectations emerged as the dominant reason supporting marital name changing for all respondents in this study. The interview data revealed that sometimes family members explicitly encouraged compliance to the tradition while at other times the respondents assumed their family expected marital name changing. Either way, it is striking the extent of influence held by family expectations and this illustrates the power of the socialization process.

Adding to the evidence of socialization is the fact that almost half of the respondents from both samples thought that marital name changing was not an important issue. That is, they accepted the social norm. Even so, the findings reveal that marital name changing is considered very important in terms of meeting expectations set by their family and by society, and for establishing family unity with their husband. Together these results show the complexity of the issue but moreover the findings demonstrate the power of the social norm of marital name changing.

Unlike responses from the questionnaire, the interviewees expressed concern about losing their personal identity. They seem to resolve this dilemma by focusing on the notion that name changing is a tradition that should be honored and is part of the marriage process. All of the interviewees have advanced 
levels of education but most of them did not think changing their name would be a disadvantage for their career. This finding is unexpected given the positive association between education and name keeping reported in previous research. It is possible that other influential factors shown in prior research, for example, differences by place of residence, might further explain this relationship.

A theme that emerged in the qualitative findings, but was not part of the quantitative questionnaire, was heteronormativity. The respondents expressed this theme by stating they wanted an outward display of unity through the name change. They expressed wanting to show other people in society their married status. This gaining of social power obtained by marital name changing is a form of social mobility, as exemplified by the respondent who stated, "It's a name upgrade!" The perception of gaining power at the societal level is supported at the personal level by the finding that very few respondents in this study agreed with the idea that name changing gives the husband power over the wife. Prior research indicates that both men and women agreed that women do not have a lot of power in society, despite there being no significant gender difference in reports of feeling personally powerful (Powers \& Reiser, 2005). In a patriarchal society, gaining approval from men is a form of power (Kimmel, 2011) and accepting the practice of marital name changing complies with gendered expectations. The respondents in the present study frame the issue of marital name changing as an achievement for women rather than a reinforcement of women's subordinate social status.

There are several limitations to this study that must be noted. There are known biases in both qualitative and quantitative research (Johnson \& Onwuegbuzie, 2004). The samples used for the analyses are not generalizable. The focus on women respondents excluded men's views about marital name changing. It is reasonable to think that women's reasons about name changing are not independent of their future spouse's and this is an area for future research.

\section{Conclusion}

The findings from this study illustrate how being socialized in a patriarchal society contributes to conformity with gendered traditions and adherence to social norms. That is, women are likely to follow the practice of dropping their name and taking their husband's name upon marriage. A key contribution of this study is the use of mixed methods to gain a deeper understanding of reasons for marital name changing. Together the findings suggest that women's perceptions of their family's expectations are a key reason motivating them to practice marital name changing. However, as confirmed by both samples of data, women expressed mixed and sometimes inconsistent reasons regarding marital name changing. Future research on this topic would add to the body of knowledge by exploring the reasons given by married women who kept their birth name, or who chose to hyphenate last names, or who created with their spouse a new name. The examples of those who do not comply with the social norm would likely provide more insight into how cultural traditions are shaped, maintained and changed.

\section{Acknowledgments}

We extend our gratitude to the undergraduate and graduate students who contributed to this project. We thank the anonymous reviewers for their helpful comments.

\section{REFERENCES}

Berger, P., \& Luckman, T. (1966). The social construction of reality: A treatise in the sociology of knowledge. New York: Doubleday Anchor.

Blakemore, J. E. O., Lawton, C. A., \& Vartanian, L. R. (2005). I can’t wait to get married: Gender differences in drive to marry. Sex Roles, 53, 327-335.

Blumer, H. (1969). Symbolic interactionism: Perspective and method. Englewood Cliffs, NJ: Prentice-Hall.

Cheshire, J., Longley, P., \& Mateos, P. (2011). What's in a surname? National Geographic, 20-21.

Emens, E. F. (2007). Changing name changing: Framing rules and the future of marital names. University of Chicago Law Review, 74, 761863.

Emens, E. F. (2011). A simple hyphen will do. The New York Times. http://www.nytimes.com/roomfordebate/2011/07/03/marriage-the-ne xt-chapter/marriage-options-a-simple-hyphen-will-do

Garfinkel, H. (1967, 1984). Studies in ethnomethodology. Malden, MA: Blackwell.

Goffman, E. (1959). The presentation of self in everyday life. New York: Anchor.

Gooding, G., \& Kreider, R. (2010). Women’s marital naming choices in a nationally representative sample. Journal of Family Issues, 31, 681-701.

Hoff, J. (1991). Law, gender, and injustice: A legal history of US women. New York: New York University Press.

Hoffnung, M. (2006). What's in a name? Marital name choice revisited. Sex Roles, 55, 11-12.

Johnson, B., \& Onwuegbuzie, A. J. (2004). Mixed methods research: A research paradigm whose time has come. Educational Researcher, $55,14-26$.

Johnson, D. R., \& Scheuble, L. K. (1995). Women's marital naming in two generations: A national study. Journal of Marriage and Family, 57, 724-732.

Kerr, A. M. (1992). Lucy Stone: Speaking out for equality. Rutgers University Press.

Kimmel, M. (2011). The gendered society (4th ed.). New York: Oxford.

Kopelman, R. E., Shea-Van Fossen, R. J., Paraskevas, E., Lawter, L., \& Prottas, D. (2009). The bride is keeping her name: A 35-year retrospective analysis of trends and correlates. Social Behavior \& Personality: An International Journal, 37, 687-700.

Million, J. (2003). Woman's voice, woman's place: Lucy Stone and the birth of the woman's rights movement. Westport, Conn: Praeger.

Plano Clark, V. L., Garrett, A. L., \& Leslie-Pelecky, D. L. (2010). Applying three strategies for integrating quantitative and qualitative databases in a mixed methods study of a nontraditional graduate education program. Field Methods, 22, 154-174.

Powers, R. S., \& Reiser, C. (2005). Gender and self-perceptions of social power. Social Behavior \& Personality: An International Journal, 33, 553-567.

Scheuble, L. K., Johnson, D. R., \& Johnson, K. M. (2012). Marital name changing attitudes and plans of college students: Comparing change over time and across regions. Sex Roles, 66, 282-292.

Scheuble, L., \& Johnson, D. R. (1993). Marital name change: Plans and attitudes of college students. Journal of Marriage \& Family, 55, 747754.

Schutz, A. (1932, 1967). The phenomenology of the social world. Evanston, IL: Northwestern University Press.

Smith, D. (1987). Everyday world as problematic: A feminist sociology. Boston Northeastern University Press. 